\title{
Leakage current signal parameter of various surface roughness conditions of field-aged polymer insulators
}

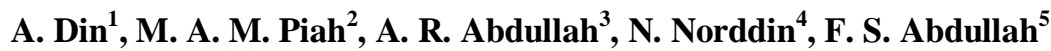 \\ ${ }^{1,3,4}$ Universiti Teknikal Malaysia Melaka, Malaysia \\ ${ }^{2}$ Universiti Teknologi Malaysia \& Institute of High Voltage and High Current, Malaysia \\ ${ }^{5}$ Universiti Malaysia Perlis, Malaysia
}

\begin{tabular}{l} 
Article Info \\
\hline Article history: \\
Received Feb 15, 2020 \\
Revised Apr 17, 2020 \\
Accepted Apr 29, 2020
\end{tabular}

Keywords:

Leakage current

Polymer insulator

Spectrogram analysis

Surface roughness

Total harmonic distortion

\begin{abstract}
This paper presents the signal parameter of leakage current based on various surface roughness degradation conditions for field-aged high voltage polymer insulators. The arithmetical mean of surface roughness is measured accordingly, and also the surface leakage current signal is captured effectively using data acquisition device via the electrical stress test. With the variation of fieldaged insulators ages which include 6-year, 12-year and 18-year, they have been mechanically tested using a surface roughness tester along with electrical testing by using the standard method of inclined plane test. The surface roughness data are recorded meanwhile the leakage current signals are further analyzed using Spectrogram to extract the signal parameter. These include the instantaneous root mean squared current, the instantaneous total harmonic distortion, the instantaneous total non- harmonic distortion and the instantaneous total waveform distortion. From the results of the comparative study, it has shown that the statistical quantity of leakage current signal parameters is responding in an increasing trend with respect to the incremental of the surface roughness. Thus, the signal parameters of the leakage current are able to indicate the degradation conditions of insulator surface.
\end{abstract}

Copyright $@ 2020$ Institute of Advanced Engineering and Science. All rights reserved.

\section{Corresponding Author:}

M. A. M. Piah,

Institute of High Voltage and High Current,

School of Electrical Engineering, Faculty of Engineering,

Universiti Teknologi Malaysia, 81310 Johor Bahru, Johor, Malaysia.

Email: fendi@utm.my

\section{INTRODUCTION}

Contemporary with the development of insulating material technology, the outdoor polymeric insulator is becoming more popular and were commercially used in power industry. Its advantages over a non-polymeric insulator in certain application include ease of installation [1], uniqueness of its hydrophobic properties and able to achieve lightweight reduction up to 90\% [2]. However, this organic-based insulator is still experiencing degradation that is affected by the combination of several elements such as mechanical, electrical, heat stress and environmental stresses during its operation [3]. These multiple stresses will accelerate degradation rapidly which can promote surface hydrophobic loss [4], surface leakage current [5], partial discharge, surface tracking [2], erosion [6] and in the worst case its might completely failure [7].

By realizing the significant of preventative measures to minimize potential high-risk impacts due to the degradation, researchers around the world have worked out on various methods of analysis. Among them including analysis of physical assessment such as surface roughness and hydrophobicity, chemical properties [8] and electrical properties. Surface roughness $[9,10]$ and leakage current (LC) analysis $[11,12]$ are the most common analysis that could be further explored.

However, there are several methods that have been implemented in the LC signal analysis, such as time domain, frequency domain and time-frequency distributions (TFD). In this study, Spectrogram as one of 
the TFD analysis available is used due to its compatibility to suit with the non-stationary characteristics of the LC signals whereby the signal content changes in time throughout the insulator testing. The advantage of this method has been capitalized by [11] to investigate different stages of LC discharges activities which are correlated to the level of polluted insulator surfaces.

Unlike the time domain and frequency domain that can only analyze LCs in a time series separately, another advantage of this method is that a signal can be represented in time-frequency representation (TFR). The Spectrogram technique will utilize both time and frequency domain simultaneously. Thus, it has the potential to enable LC parameters in both domains to be extracted from Spectrogram. The color intensity of TFR represents various amplitude of energy distributed at a particular frequency and time.

This study is intended to further extend the investigation that has been done in [9]. The response of the LC signal that is captured in the standard methods of the electrical stress test with respect to the measured surface roughness, $R_{a}$ are analysed accordingly. In this analysis, the instantaneous LC signal parameters are extracted from the captured LC signal using Spectrogram as described in subsection 2.4. The signals will be also calculated statistically in order to compare with the arithmetical mean surface roughness data.

The testing materials utilized are the three units of field-aged surge arrester's housing insulator which was obtained from Tenaga Nasional Berhad (TNB), the Malaysian national power company. Originally, these field-aged insulators were removed from the transmission main intake (Pencawang Masuk Utama, PMU) in Pagoh (6-year), Simpang Renggam (18-year) and Plentong (12-year) power substation located along the coast in the state of Johor, Malaysia. These insulators have been in the field of services for number of years.

\section{BACKGROUND THEORY}

In this section, the first two subsections will present prior study related to the surface roughness condition factors and its relationship with the LC signal parameters. And meanwhile, in the next two subsections, the mathematical equations of the Spectrogram and each of the LC signal parameter in extraction process are indicated.

\subsection{Factors of the insulator age and environmental stress that affected the $R \mathbf{R}$}

According to Haddad et al., [13], the service age of insulator will greatly affect the value of $R_{a}$. When the age is longer, the larger of $R_{a}$ will be acquired. This has been acknowledged by Khan [10] in his study using the new samples in which it can be observed that the nature of surface insulator much smoother, homogenous and minimal porous surface as compared to the aged insulators. Meanwhile, related to the environmental stress effect, the condition of $R_{a}$ will be getting severe when the stresses themselves are worst. For example, when the dust and accumulated pollution have affected the surface roughness of the insulator, the dielectric performance will degrade after a long hours operation of the actual power system.

\subsection{Relationship of Ra with the LC root mean squared, Irms and the LC harmonic component}

Suwarno [14] in his observation has found out that the rms of LC magnitude is correlated with the surface resistance of the insulator. Larger magnitude of LC will generate more heat on the insulator surface and may promote the degradation of insulator compare to normal condition with small LC magnitude. Sarathi et al., [15], by using specimens with water aged and surface roughened have discovered the timeinvariant nature of the magnitude of LC flow during tracking studies. The magnitude of LC is increasing significantly at the time of failure due to tracking. This finding has been acknowledged by Darwison et al., [16], justified that as the LC is getting higher, the quality of the insulator will drop thus will shorten lifetime of the insulator in the insulation system.

Suda [17] has analyzed the odd order harmonics and noticed that the odd order of harmonic components such as $50 \mathrm{~Hz}, 150 \mathrm{~Hz}$, and $250 \mathrm{~Hz}$, will have high intensity when strong local arcs occur on the insulator surface. Sarathi et al., [15] have discovered that under the aged and un-aged silicone rubber insulators during surface tracking phenomena, the fluctuation of percentage on the odd harmonic content will occur. Meanwhile, Douar et al., [18] have reported that the LC odd harmonics energy have increased proportionally with the increase of polluted layer width while investigating on the LC using the Welch frequency spectrum.

\subsection{Spectrogram analysis}

Spectrogram is the time-frequency representation (TFR) of the Short-Time Fourier Transform (STFT). The Spectrogram is obtained by a modulus squared magnitude of the STFT. It represents a threedimensional of the signal energy with respect to time and frequency. Basically, this representation reflects on how the frequency content changes over time. The Spectrogram is derived as in (1). 


$$
S_{x}(t, f)=\left|\int_{-\infty}^{\infty} h(\tau) w(\tau-t) e^{-j 2 \pi f \tau} d \tau\right|^{2}
$$

where $h(\tau)$ is the input signal and $w(\tau-t)$ is the observation window.

In the case of LC which is supplied by a fundamental source frequency of $50 \mathrm{~Hz}$, Jayasundara et al., [19] have selected a Hann window because of its lower peak side lobe. This will give insignificant effect on other frequencies around fundamental value and harmonic frequencies. In the related studies, Abidin et al., [20] have used the STFT and Spectrogram to develop an online monitoring system and allow the user to identify leakage current performance in a real time interface. In other application, Too et al., [21] have used the Spectrogram as to investigate the relationship between the electromyography (EMG) signal and muscle characteristic. In other related work, Jopri et al., [22] have implemented the TFR using Spectrogram to detect the harmonic signals which represent total harmonic distortion (THD) and total nonharmonic distortion $(T n H D)$ voltage in power distribution system.

\subsection{LC signal parameter}

Abdullah et al., [23] have explored the performance of polymeric and non-polymeric insulation material in contaminated condition. The Spectrogram is used to extract instantaneous LC signal parameter such as root mean squared current $\left(I_{r m s}\right)$, root mean squared fundamental current $\left(I_{1 r m s}\right)$, total harmonic distortion $\left(I_{T H D}\right)$, total non-harmonic distortion $(I)_{T n H D}$, and total waveform distortion $\left(I_{T W D}\right)$. These parameters are estimated instantaneously in order to develop and monitor the state of the materials insulating condition. The parameters are derived as in the (2) to (6): instantaneous root mean squared current $\left(I_{r m s}\right)(t)$ is derived as:

$$
I_{r m s}(t)=\sqrt{\int_{0}^{f_{\max }} S_{X}(t, f) d f}
$$

where $S_{x}(t, f)$ is time-frequency distribution and $f_{\max }$ is maximum frequency of interest.

Instantaneous root mean squared fundamental current $\left(I_{1 r m s}\right)(t)$ is defined as the root mean squared current at power system frequency and can be calculated as:

$$
I_{1 r m s}(t)=\sqrt{2 \int_{f_{l o}}^{f_{h i}} S_{X}(t, f) d f} \quad \text { and } f_{h i}=f_{1}+\frac{\Delta f}{2}, f_{l o}=f_{1}-\frac{\Delta f}{2}
$$

where $f_{l}$ is the fundamental frequency that corresponds to the power system frequency and $\Delta f$ is the bandwidth which is set to $50 \mathrm{~Hz}$.

$T H D$ is the relative signal energy present at non-fundamental frequencies and written as:

$$
I_{T H D}(t)=\frac{\sqrt{\sum_{h=2}^{H} I_{h, r m s}(t)^{2}}}{I_{1 r m s}(t)}
$$

where $I_{h, r m s}(t)$ is root mean squared harmonic current and $H$ is the highest measured harmonic component.

Nonharmonics are not multiple integer signal components frequency of the power system frequency. Therefore, $T n H D$ is referred as distinguishing between nonharmonic and noise, and is calculated as:

$$
I_{T n H D}(t)=\frac{\sqrt{I_{r m s}(t)^{2}-\sum_{m=2}^{M} I_{m, r m s}(t)^{2}}}{I_{1 r m s}(t)}
$$

where $I_{m, r m s}(t)$ is instantaneous root mean squared nonharmonic current and $M$ is the highest measured nonharmonic component.

Total waveform distortion (TWD) consists of harmonic distortion and nonharmonic distortion. It can be defined as:

$$
I_{T W D}(t)=\sqrt{I_{T H D}(t)^{2}+I_{T n H D}(t)^{2}}
$$

\section{RESEARCH METHOD}

The EPDM silicone rubber insulator in the polyvinyl nitrate (PVN) polymer station class surge arrester (SA) is used for testing. The technical details can be referred to the product datasheet in [24]. 


\subsection{Workflow of testing and analysis implementation}

The process of testing and analysis of the samples is represented in Figure 1.

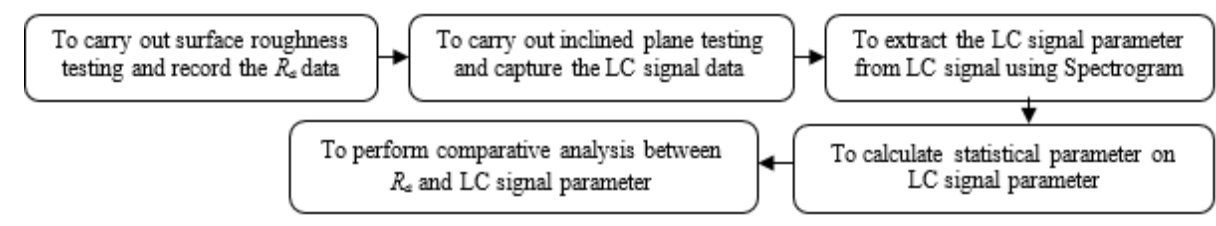

Figure 1. Workflow of sample testing and analysis

\subsection{Tests equipment setup}

The equipment that has been used for surface roughness test is Mitutoyo portable surface roughness tester Surftest SJ-410 Series Model [25]. The calibration is carried out prior to the testing. The suitable jig and water levelling tool have been used to tune the correct angle configuration between stylus tip and surface of insulator sample. The evaluation sampling length is set to $25 \mathrm{~mm}$. Others parameter are set according to the ISO1997 Standard. The experimental setup for inclined-plane tracking (IPT) Test that has been conducted is based on the BS EN 60587 [26]. Basically the setup is similar with the IPT test conducted by Piah et al., [27] as shown in Figure 2.

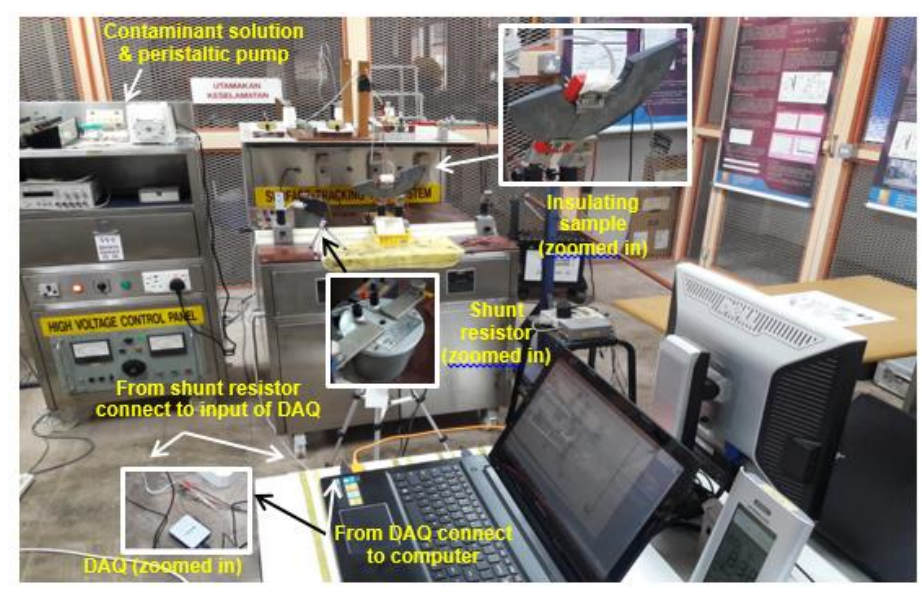

Figure 2. Setup of IPT test equipment

This IPT test has been carried out according to the Method 1 test, whereby a constant tracking voltage of $3.5 \mathrm{kV}$ is applied to simulate continuous tracking voltage. The LC signal that responded to different value of surface roughness is crucial and it is recorded continuosly by the data acquisition device (DAQ) for further analysis purpose. The combination of the National Instrument NI-USB 6001 DAQ and LabView Software have been used for the LC signal data capturing and storing processes. The value of LC can be determined by dividing a voltage drop against the $100 \Omega$ shunt resistor. A testing period of 60 minutes with the constant voltage of $3.5 \mathrm{kV}$ is implemented for each specimen, while the contaminant conductivity is set to $2.56 \mathrm{mS} / \mathrm{cm}$ and its flow rate at $0.3 \mathrm{ml} / \mathrm{min}$ which is equivalent to $4.2 \mathrm{rpm}$ of peristaltic pump motor speed.

\section{RESULTS AND DISCUSSION}

Four points of arithmetical mean surface roughness, $R_{a}$ data for each ten field-aged sample are recorded. Then, one of the points with the highest $R_{a}$ has been choosen to be further tested in electrical stress test. The $R_{a}$ for each sample of three groups' field-aged polymer insulator and its controlled samples (CS) surface rougness, $R_{a c s}$ as the reference sample are presented in Table 1 . The controlled samples are prepared by clearing out contaminations on the 12/20 sample in each field-aged group using isoprophyl alcohol and rinse it with distilled water [26]. 
As been indicated in Table 1 , the value of Racs for every group is different, whereby the $R_{a c s}-12>$ $R_{a c s}-18>R_{a c s}-6$. The $\mathrm{R}_{\text {acs }}$ results are also in line with the field-aged $R_{a}$ minimum and maximum data range. The minimum and maximum arithmetical mean surface roughness of each group and its $R_{\text {acs }}$ is shown in Table 2 . As can be seen from Table 2, the maximum range $R_{a-12 \text { max }}>R_{a-18 \max }>R_{a-6 \text { max }}$ and the minimum range $R_{a-12 \min }>R_{a-18 \min }>R_{a-6 \mathrm{~min}}$ significantly show a consistent trend of surface roughness level among the groups. This can be concluded that based on the surface roughness condition, each group had experienced different level of degradation regardless of the age of insulator. The level of degradation among the groups is increased in a sequence of 6-year, 18-year and 12-year field-aged insulators respectively. The degradation is influenced by the local pollution and environmental stresses because of they in the service at different installation areas [9].

The statistical analysis which is based on the minimum and maximum surface roughness data that are shown in Table 2 are compared with the signal parameter that gathered from IPT Test and analysed using Spectrogram in MatLab. Due to the consistency performance of surface roughness data among the groups, only one sample that is the $20 / 20$ shed sample data and output results has been chosen to be presented in details. From the the Spectrogram in Figure 3, it shows that, with the highest surface roughness value $\left(R_{a}=\right.$ $10.254 \mu \mathrm{m}$ ), the existence of non-harmonic and odd harmonic components of this insulators can be differentiated significantly compared to the others with less $R_{a}$ (in the range of $1.2 \mu \mathrm{m}$ to $1.6 \mu \mathrm{m}$ ). The signal energy indicated by the color intensity legends are also increased positively as the responses to the increment of the $R_{a}$.

Table 1. The arithmetical mean surface roughness for each sample of three groups' field-aged polymer insulator and its controlled samples

\begin{tabular}{|c|c|c|c|c|c|c|}
\hline \multirow[t]{2}{*}{ Sample no. } & \multicolumn{6}{|c|}{ Arithmetical mean surface roughness, $R_{a}$ and its controlled sample, $R_{a c s}$ of insulators } \\
\hline & 6-year field-aged & $\begin{array}{l}\text { 6-year CS } \\
R_{0 c-6} \text { (um) }\end{array}$ & $\begin{array}{l}\text { 12-year field-aged } \\
R_{0-1}(\mu \mathrm{m})\end{array}$ & 12-year CS & $\begin{array}{c}18 \text {-year field-aged } \\
R_{a-l}(\text { um) }\end{array}$ & 18-year CS \\
\hline $2 / 20$ & $\mathbf{0 . 8 9 7}$ & 0.422 & 2.028 & 0.925 & 1.161 & 0.576 \\
\hline $3 / 20$ & 1.156 & 0.422 & 1.647 & 0.925 & 1.333 & 0.576 \\
\hline $5 / 20$ & 0.866 & 0.422 & 1.510 & 0.925 & 1.259 & 0.576 \\
\hline $6 / 20$ & 0.788 & 0.422 & 1.772 & 0.925 & 1.201 & 0.576 \\
\hline $10 / 20$ & 1.016 & 0.422 & 1.826 & 0.925 & 1.078 & 0.576 \\
\hline $11 / 20$ & 1.089 & 0.422 & 1.629 & 0.925 & 1.599 & 0.576 \\
\hline $15 / 20$ & 0.645 & 0.422 & 2.507 & 0.925 & 1.736 & 0.576 \\
\hline $16 / 20$ & 0.568 & 0.422 & 4.408 & 0.925 & 1.643 & 0.576 \\
\hline $19 / 20$ & 1.285 & 0.422 & 1.243 & 0.925 & 1.439 & 0.576 \\
\hline $20 / 20$ & 1.219 & 0.422 & 10.254 & 0.925 & 1.558 & 0.576 \\
\hline
\end{tabular}

Table 2. The minimum and maximum value of the arithmetical mean surface roughness for three groups' field-aged polymer insulator

\begin{tabular}{cccccc}
\hline \multicolumn{2}{c}{ 6-year field-aged } & \multicolumn{2}{c}{ 12-year field-aged } & \multicolumn{2}{c}{ 18-year field-aged } \\
\hline \multicolumn{2}{c}{$R_{\text {acs- } 6}=0.422 \mu \mathrm{m}$} & \multicolumn{2}{c}{$R_{\text {acs- } 12=0.925 \mu \mathrm{m}}$} & \multicolumn{2}{c}{$R_{\text {acs- } 18}=0.576 \mu \mathrm{m}$} \\
$R_{a-6 \min }$ & $\boldsymbol{R}_{a-6 \max }$ & $\boldsymbol{R}_{a-12 \min }$ & $\boldsymbol{R}_{a-12 \max }$ & $\boldsymbol{R}_{a-18 \min }$ & $\boldsymbol{R}_{a-18 \max }$ \\
$0.568 \mu \mathrm{m}$ & $1.285 \mu \mathrm{m}$ & $1.243 \mu \mathrm{m}$ & $10.254 \mu \mathrm{m}$ & $1.078 \mu \mathrm{m}$ & $1.736 \mu \mathrm{m}$ \\
\hline
\end{tabular}

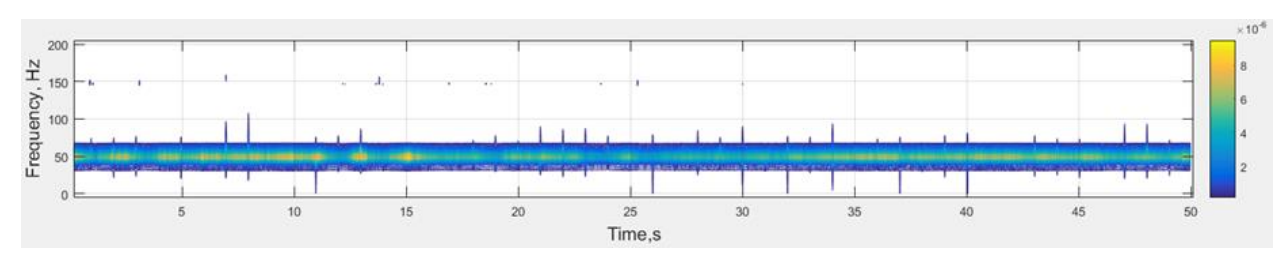

(a) $R_{a}=1.219 \mu \mathrm{m}, 6$-year field-aged $20 / 20$ shed sample insulator at the minute of $30^{\text {th }}$ in the IPT test

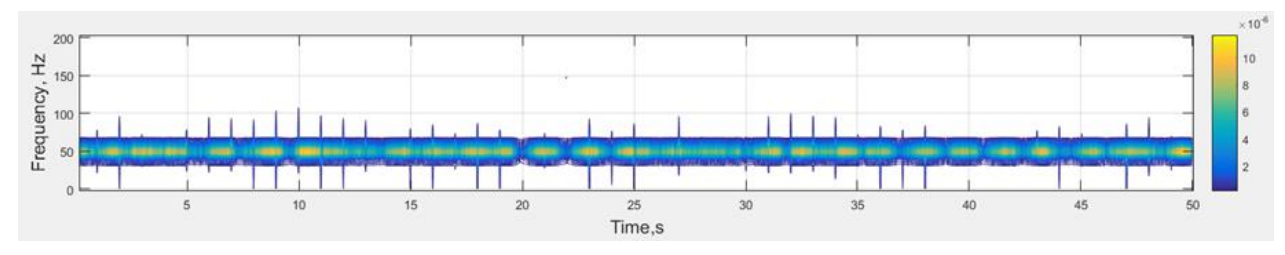

(b) $R_{a}=1.558 \mu \mathrm{m}, 18$-year field-aged $20 / 20$ shed sample insulator at the minute of $30^{\text {th }}$ in the IPT test 


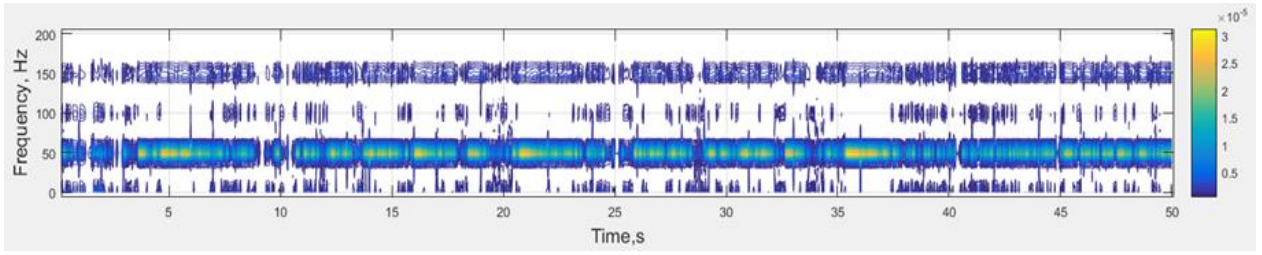

(c) $R_{a}=10.254 \mu \mathrm{m}$, for 12 -year field-aged $20 / 20$ shed sample at the minute of $30^{\text {th }}$ in the IPT test

Figure 3. TFR of Spectrogram of the instantaneous leakage current for different value of surface roughness among the three groups of field-aged insulator's shed

Table 3 shows overall average signal parameters in time and frequency domain that were extracted from the Spectrogram. The average magnitude of $I_{r m s}$ is increased and correlated with the condition in which the more roughened surface, higher of average $I_{r m s}$ will be. In the frequency domain, with a lower value of $R_{a}$ (in the range of $1.2 \mu \mathrm{m}$ to $1.6 \mu \mathrm{m}$ ), it only shows the existence of non-harmonic distortion components compared with the $R_{a}=10.254 \mu \mathrm{m}$. These results are also corresponded to the average percentage of the harmonic components in which it can be observed clearly with the increment of the \%TWD.

Table 3. The average value of LC signals parameter at the minute of $30^{\text {th }}$ for three different conditions of surface roughness

\begin{tabular}{|c|c|c|c|c|c|}
\hline \multirow{3}{*}{$\begin{array}{c}\text { Field-aged } \\
20 / 20 \text { shed } \\
\text { sample }\end{array}$} & \multirow{3}{*}{$\begin{array}{c}\text { Average value of } \\
\text { surface roughness, Ra } \\
(\mu \mathrm{m})\end{array}$} & \multicolumn{4}{|c|}{ Average value of LC signal parameter at the minute of $30^{\text {th }}$ in the IPT test } \\
\hline & & \multirow{2}{*}{$\begin{array}{l}\text { Time domain } \\
\text { Irms }(\%)\end{array}$} & \multicolumn{3}{|c|}{ Frequency domain } \\
\hline & & & THD (\%) & TnHD (\%) & TWD $(\%)$ \\
\hline 6-year & 1.219 & 0.0030 & 0.0000 & 0.0003 & 0.0003 \\
\hline 18-year & 1.558 & 0.0034 & 0.0000 & 0.0031 & 0.0031 \\
\hline 12-year & 10.254 & 0.0052 & 32.6364 & 2.1225 & 34.7136 \\
\hline
\end{tabular}

\section{CONCLUSION}

It can be concluded that the signal parameter of leakage current that have been extracted from Spectrogram have provided very significant indicator in describing the EPDM rubber insulator degradation condition based on the $R_{a}$. The results of the electrical signal parameter are correlated with the $R_{a}$ data, in which with the increment of the $R_{a}$ and the signal parameter of $I_{r m s}$, the harmonic distortion components will be also increased. Therefore, the response of LC signal parameters towards a certain threshold value of $R_{a}$ is really meaningful in order to indicate the degradation conditions of insulator surface.

\section{ACKNOWLEDGEMENTS}

The authors are gratefully acknowledged Malaysia Ministry of Higher Education (MOHE), Universiti Teknikal Malaysia Melaka (UTeM) for giving support in this study and Universiti Teknologi Malaysia (UTM) for providing facilities and support under the research grants of UTM-TDR 46, Vot.Q.J130000.3551.07G60 and UTM-TDR 46.3, Vot.Q.J130000.3551.06G14. The authors are also deeply appreciated to the Malaysian national power company, Tenaga Nasional Berhad, TNB (Distribution), Melaka for their assistance in providing the insulator samples used in this study.

\section{REFERENCES}

[1] R. Tripathi, G. Grzybowski, and R. Ward, "Electrical degradation of $15 \mathrm{kv}$ composite insulator under accelerated aging conditions," in 2013 IEEE Electrical Insulation Conference(EIC), Ottawa, ON, pp. 404-408, 2013.

[2] A. Madi, Y. He, L. Jiang, and B. Yan, "Surface Tracking on Polymeric Insulators Used in Electrical Transmission Lines," Indonesian Journal of Electrical Engineering and Computer Science (IJEECS), vol. 3, no. 3, pp. 639-645, 2016.

[3] A. A. Salem, et al., "The effect of insulator geometrical profile on electric field distributions," Indonesian Journal of Electrical Engineering and Computer Science (IJEECS), vol. 14, no. 2, pp. 618-627, 2019.

[4] I. Ahmadi-Joneidi, A. Majzoobi, A. Shayegani-Akmal, H. Mohseni, and J. Jadidian, "Aging evaluation of silicone rubber insulators using leakage current and flashover voltage analysis," IEEE Transactions on Dielectrics and Electrical Insulation, vol. 20, no. 1, pp. 212-220, 2013.

[5] A. A. Salem, et al., "Proposal of a Dynamic Numerical Approach in Predicting Flashover Critical Voltage," International Journal of Power Electronics and Drive System (IJEPDS), vol. 10, no. 2, pp. 602-610, 2019. 
[6] R. A. Ghunem, "Using the Inclined-Plane Test to Evaluate the Resistance of Outdoor Polymer," IEEE Electrical Insulation Magazine, vol. 31, no. 5, pp. 16-22, 2015.

[7] G. Haddad, K. L. Wong, and P. Petersen, "Evaluation of the Aging Process of Composite Insulator based on Surface Charaterisation Techniques and Electrical Method," IEEE Transactions on Dielectrics and Electrical Insulation, vol. 23, no. 1, pp. 311-318, 2016.

[8] M. K. Moghadam, M. Taheri, S. Gharazi, M. Keramati, M. Bahrami, and N. Riahi, "A study of composite insulator aging using the tracking wheel test," IEEE Transactions on Dielectrics and Electrical Insulation, vol. 23, no. 3, pp. 1805-1811, 2016.

[9] A. Din, M. A. M. Piah, A. R. Abdullah, and N. F. Kasri, "Surface roughness condition of field-aged polymer insulators at different installation area," Indonesian Journal of Electrical Engineering and Computer Science (IJEECS), vol. 15, no. 2, pp. 600-608, 2019.

[10] Y. Khan, "Degradation of High Voltage Polymeric Insulators in Arid Desert's Simulated Environmental Conditions," American Journal of Engineering and Applied Sciences, vol. 2, no. 2, pp. 438-445, 2009.

[11] N. Dhahbi-megriche and A. Beroual, "Time-frequency analyses of leakage current waveforms of high voltage insulators in uniform and non-uniform polluted conditions," IET Science, Measurement \& Technology, vol. 9, no. 8, pp. 945-954, 2015.

[12] W. Song, et al., "Aging characterization of high temperature vulcanized silicone rubber housing material used for outdoor insulation," IEEE Transactions on Dielectrics and Electrical Insulation, vol. 22, no. 2, pp. 961-969, 2015.

[13] G. Haddad, K. L. Wong, and P. Petersen, "Evaluation of the hydrophobic property of composite insulators using Dynamic Drop Test," Proceedings of 2014 International Symposium on Electrical Insulating Materials, Niigata, pp. 280-283, 2014.

[14] Suwarno, "Leakage Current Waveforms of Outdoor Polymeric Insulators and Possibility of Application for Diagnostics of Insulator Conditions," Journal of Electrical Engineering and Technology, vol. 1, no. 1, pp. 114-119, 2006.

[15] N. Sarathi, R; Chandrasekar, S; Venkataheshaiah, C; Yoshimura, "Investigation of Tracking Phenomena in Silicone Rubber Insulation Material Through Leakage Current Analysis," in National Power Systems Conference, NPSC 2004, pp. 395-400, 2004.

[16] Darwison, S. Arief, H. Abral, A. Hazmi, M. H. Ahmad, and E. P. Waldi, "A leakage current estimation based on thermal image of polymer insulator," Indonesian Journal of Electrical Engineering and Computer Science (IJEECS), vol. 16, no. 3, pp. 1096-1106, 2019.

[17] T. Suda, "Frequency characteristics of leakage current waveforms of a string of suspension insulatorsin," IEEE Transactions on Power Delivery, vol. 20, no. 1, pp. 481-487, 2005.

[18] M. A. Douar, A. Mekhaldi, and M. C. Bouzidi, "Frequency analysis of the leakage current under non uniform polluted conditions on one insulator plane model," 2010 Annual Report Conference on Electrical Insulation and Dielectic Phenomena, West Lafayette, IN, pp. 1-4, 2010.

[19] H. I. S. Jayasundara, W. P. S. Sudarshani, and M. a. R. M. Fernando, "Leakage Current Patterns on High Voltage Insulators: Analysis on Frequency and Time-frequency Domains," 2008 IEEE Region 10 and the Third international Conference on Industrial and Information Systems, Kharagpur, pp. 1-6, 2008.

[20] N. Q. Z. Abidin, A. R. Abdullah, N. Norddin, and A. Aman, "Online Surface Condition Monitoring System using Time Frequency Distribution on High Voltage Insulator," 2013 IEEE 7th International Power Engineering and Optimization Conference (PEOCO), Langkawi, pp. 513-517, 2013.

[21] J. Too, A. R. Abdullah, N. M. Saad, N. M. Ali, and T. N. S. T. Zawawi, "Featureless EMG pattern recognition based on convolutional neural network," Indonesian Journal of Electrical Engineering and Computer Science (IJEECS), vol. 14, no. 3, pp. 1291-1297, 2019.

[22] M. H. Jopri, A. R. Abdullah, T. Sutikno, M. Manap, M. R. A. Ghani, and M. R. Yusoff, "A Critical Review of Time-frequency Distribution Analysis for Detection and Classification of Harmonic Signal in Power Distribution System," Indonesian Journal of Electrical Engineering and Computer Science (IJEECS), vol. 8, no. 6, pp. 4603-4618, 2018.

[23] A. R. Abdullah, N. Norddin, N. Q. Z. Abidin, A. Aman, and M. H. Jopri, "Leakage Current Analysis on Polymeric and Non- Polymeric Insulating Materials Using Time- Frequency Distribution," 2012 IEEE International Conference on Power and Energy (PECon), Kota Kinabalu, pp. 979-984, 2012.

[24] “PVN Polymer Station Class Arresters," Hi-Tension News, no. 1051, pp. 1-4, 1993.

[25] Mitutoyo, "SURFTEST SJ-410 Series," M3 Solution Centers, no. 2196, America, pp. 1-12, 2015.

[26] BS EN, "Electrical insulating materials used under severe ambient conditions-Test methods for evaluating resistance to tracking and erosion (BS EN 60587:2007)," British Standars, vol. 3. pp. 1-14, 2007.

[27] M. A. M. Piah, A. Darus, and A. Hassan, "Leakage Current and Surface Discharge Phenomena: Effect on Tracking and Morphological Properties of LLDPE-Natural Rubber Compounds," Proceedings of the 7th International Conference on Properties and Applications of Dielectric Materials (Cat. No.03CH37417), Nagoya, Japan, vol. 1, pp. 347-350, 2003. 


\section{BIOGRAPHIES OF AUTHORS}
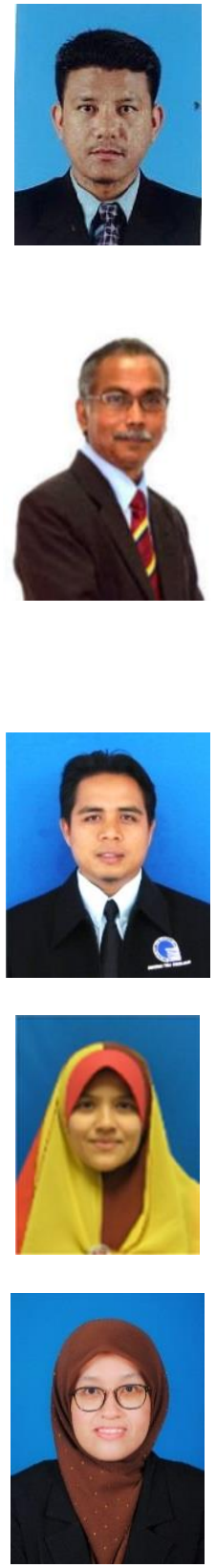

Asri Din (A. Din) was born in Melaka, Malaysia on June 11, 1977. He has received the B. Eng in Electrical and Electronics from Universiti Teknologi Malaysia in 2000 and M. Eng in Electrical Energy and Power System from Universiti Malaya, Malaysia in 2008. He is a senior lecturer of Universiti Teknikal Malaysia Melaka and has been working there since December 2002. Prior to this, he used to work as a Product Engineer at Ceemax Technology in Melaka from 2000 to 2002. Currently he is undergoing his $\mathrm{PhD}$ study on the outdoor polymer insulator degradation performance monitoring at the Institute of High Voltage and High Current (IVAT) under School of Electrical Engineering, Faculty of Engineering, Universiti Teknologi Malaysia.

Dr. Mohamed Afendi Mohamed Piah (M.A.M. Piah) is an associate professor at School of Electrical Engineering, Faculty of Engineering, Universiti Teknologi Malaysia and a fellow member of the Institute of High Voltage and High Current (IVAT). He is also a Signatory of High Voltage Testing accreditation lab of ISO/IEC 17025. He received the B. Elect. Eng. degree from Universiti Teknologi Malaysia in 1986, M.Sc in Power System from University of Strathclyde, UK in 1990 and $\mathrm{PhD}$ in High Voltage Engineering from Universiti Teknologi Malaysia in 2004. He was appointed as an assistant director (Test and Calibration Division) of IVAT from 1996-2000 and Deputy Director of IVAT from 2007-2009. He has been involved in testing and calibration of high voltage equipments. His research interests include high voltage insulation diagnostic and co-ordination, electrical discharges, polymer nanocomposites insulating materials and insulator condition monitoring.

Dr. Abdul Rahim Abdullah (A. R. Abdullah) was born in Kedah, Malaysia on 1979. He received his B. Eng., Master Eng., and PhD Degree from Universiti Teknologi Malaysia in 2001, 2004 and 2011 in Electrical Engineering and Digital Signal Processing respectively. He is currently an Associate Professor at the Department of Electrical Engineering, Deputy director of Center for Edu- Tourism and Chief of Advanced Digital Signal Processing (ADSP) Lab, Universiti Teknikal Malaysia Melaka (UTeM).

Nurbahirah Norddin received her B. Eng degree in Electrical Engineering (Power Electronic \& Drives) in 2011 and M. Eng in Electrical Engineering from Universiti Teknikal Malaysia Melaka (UTeM) in 2014. Currently she is a lecturer at Universiti Teknikal Malaysia Melaka (UTeM) and her interest involves high voltage and signal processing.

Farrah Salwani Binti Abdullah was born in Terengganu, Malaysia on December 21, 1986. She received B. Eng (Hons) and M. Eng in Electrical Engineering from Universiti Tun Hussein Onn Malaysia (UTHM). She is a member of Board Engineer Malaysia and Institute Engineer Malaysia. She is currently pursuing her $\mathrm{PhD}$ at the Institute of High Voltage and High Current (IVAT), School of Electrical Engineering, Universiti Teknologi Malaysia (UTM). Her main research interest includes high-voltage engineering and outdoor insulator condition monitoring. 